\title{
RANCANG BANGUN PANDUAN PENCAK SILAT BERBASIS WEB MOBILE (STUDI KASUS PERSAUDARAAN SETIA HATI)
}

\author{
Ferdiyani Haris \\ Sistem Informasi - STMIK Palangkaraya \\ Jl. G. Obos No. 114 Palangkaraya, Kalimantan Tengah \\ E-mail : sabila006@gmail.com
}

\begin{abstract}
ABSTRAK
Dalam dunia programan website aplikasi berbasis mobile tumbuh dengan sangat pesat sehingga bertambah banyaknya perangkat mobile phone, Jquery Mobile merupakan salah satu framework yang digunakan untuk membuat aplikasi web mobile. Jquery Mobile merupakan framework yang dibangun di atas jquery menyediakan berbagai element antarmuka pengguna (user interface) dalam pembuatan aplikasi web mobile. Pencak silat adalah olahraga bela diri yang terdiri dari gerakan jasmani yang lemah gemulai namun penuh tenaga dan dilandasi dengan rohani yang berbudi luhur. Dalam bela diri pencak silat ini mengandung unsur bela diri, olahraga, seni dan budaya yang berisi teknik pembelaan dan penyerangan, Aplikasi panduan pencak silat persaudaraan setia hati terate berbasis web mobile bertujuan untuk memberikan informasi kepada anggota mengenai informasi pencak silat persaudaraan setia hati terate palangkaraya secara online. Metode-metode yang digunakan dalam penelitian ini meliputi metode pengumpulan data (observasi, wawancara, kepustakaan, dokumentasi) metode pengembangan sistem menggunakan waterfall, jenis penelitian adalah penelitian dan pengembangan, metode pengujian menggunakan Black Box Testing.
\end{abstract}

Kata Kunci : Aplikasi, Framework, Jquery Mobile, Website

\begin{abstract}
In the world of mobile-based application web site programming that has grown by greatly enhancing mobile devices, Jquery Mobile is one of the frameworks used to create mobile web applications. Jquery Mobile is a framework built on Jquery providing various user interface elements (user interfaces) in making mobile web applications. Pencak silat is a martial sport that consists of physical movements that are graceful but full of strength and are based on virtuous soldiers. In martial arts martial arts contain elements of martial arts, sports, arts and culture that contain defense and assault techniques, the application of pencak silat fraternity applications of mobile heart-based mobile terate fraternity helps provide information to participants information on martial arts fraternity loyal heart terat palangkaraya on line. The methods used in this study include data collection methods (observation, interviews, literature, documentation) system development methods using waterfalls, the type of research is research and development, testing methods using Black Box Testing.
\end{abstract}

Keywords : Aplikasi, Framework, Jquery Mobile, Website

\section{Pendahuluan}

Seiring dengan perkembangan teknologi yang begitu pesat kebutuhan akan teknologi informasipun sangat penting dalam segala aspek bidang kehidupan. Salah satunya melalui perkembangan internet yang merupakan salah satu media informasi yang telah terbukti sangat efektif dan efisien dalam menangani sistem pengolahan data maupun penyebaran informasi. Penyebaran informasi melalui perkembangan teknologi internet dapat diakses oleh siapa saja, kapan saja dan dimana saja karena informasi yang dihasilkan mengandung nilai yang benar, cepat dan akurat. Sehingga dapat mendukung keberhasilan kinerja pada suatu organisasi baik dalam instansi pemerintah maupun swasta dalam mencapai tujuannya.

Pencak silat adalah olahraga bela diri yang terdiri dari gerakan jasmani yang lemah gemulai namun penuh tenaga dan dilandasi dengan rohani yang berbudi luhur. Dalam bela diri pencak silat ini mengandung unsur bela diri, olahraga, seni dan budaya yang berisi teknik pembelaan dan penyerangan Pencak silat merupakan olahraga bela diri khas dari Indonesia. Pencak Silat memiliki Badan resmi yaitu Ikatan Pencak Silat Seluruh Indonesia (IPSI).

Berdasarkan observasi yang dilakukan penulis pada komesariat cabang Persaudaraan Setia Hati 
Terate di Palangkaraya masih banyak anggota yang belum menguasai materi berupa Pukulan, Tendangan, Bantingan, dan jurus serta sebagian anggota masih ada yang belum mengenali sesama anggota PSHT di Palangkaraya. Ketua cabang PSHT Palangkaraya sangat mengharapkan adanya aplikasi untuk mengatasi permasalahan tersebut. Karena dengan adanya aplikasi ini nantinya akan mempermudah pelatih memberi materi kepada siswa persaudaraan setia hati terate. Penelitian ini menggunakan Web Mobile karena aplikasi ini bisa diakses kapan saja dan dimana saja, hanya memerlukan koneksi internet dan perangkat handphone jenis apa saja yang memiliki jaringan internet dan juga bisa diakses menggunakan komputer atau laptop.

\section{Kajian Teori}

\section{A. Panduan}

Menurut kamus besar bahasa Indonesia, kata panduan berasal dari kata Pandu yang berarti penunjuk jalan atau perintis jalan, sedangkan untuk kata pandu sendiri dalam buku berarti petunjuk.

\section{B. Pencak Silat}

Menurut Syukur dalam Sucipto, (2001:26mengatakan Pencak adalah gerakan langkah keindahan dengan menghindar, yang disertakan gerakan berunsur komedi. Pencak dapat dipertontonkan sebagai sarana hiburan. Sedangkan silat adalah unsur teknik bela diri menangkis, menyerang dan mengunci yang tidak dapat diperagakan di depan umum.

\section{Web Mobile}

Web Mobile adalah halaman web yang dapat di akses dengan menggunakan perangkat komunikasi tanpa terkendala ruang dan waktu.

Menurut Prasetyo (2005) mengatakan bahwa Web Mobile adalah sebuah teknologi baru yang telah mengakomodasi kebutuhan akan akses internet melalui perangkat mobile (bergerak). Jika sebelumnya web hanya dapat di akses melalui komputer, maka dengan adanya teknologi web mobile, sebuah web akan dapat diakses melalui perangkat mobile (Ponsel, PDA, Tablet, dan Smatphone) yang terhubung pada sebuah jaringan telekomunikasi.

\section{Black Box Testing}

Menurut Pressman (2001:459) pada pengujian Black-Box, pengujian dilakukan dengan objek yang diuji terfokus kepada kebutuhan fungsional dari perangkat lunak. Pengujian Black-Box memungkinkan pembuat perangkat lunak untuk menentukan kondisi yang terjadi untuk suatu masukan yang akan menjalankan semua kebutuhan fungsional dari perangkat lunak yang dibuat.
Menurut Riyanto (2011:9), XAMPP merupakan paket PHP dan MySQL berbasis Open Source, yang dapat digunakan sebagai Tool pembantu pengembangan aplikasi berbasis PHP.

Fungsinya adalah sebagai server yang berdiri sendiri (localhost), yang terdiri atas program Apache HTTP Server, MySQL Database, dan penerjemah bahasa yang ditulis dengan bahasa pemrograman PHP dan Perl. Nama XAMPP merupakan singkatan dari X (empat sistem operasi apapun), Apache, MySQL, PHP, dan Perl. Program ini tersedia dalam GNU (General Public License) dan bebas, merupakan Web Server yang mudah digunakan yang dapat melayani tampilan halaman Web yang dinamis.

\section{Perancangan Sistem}

Pada tahap desain proses ini, penulis menggunakan notasi UML (Unified Modeling Language), sebagai case tool dalam merancang proses Website, yakni dengan membuat Use Case Diagram, Activity Diagram, Class Diagram dan Sequence Diagram.

\section{A. Use Case Diagram}

Diagram use case mendeskripsikan sebuah interaksi antara satu atau lebih aktor dengan sistem yang akan dibuat. Diagram use case digunakan untuk mengetahui fungsi apa saja yang ada di dalam sebuah sistem dan siapa saja yang berhak menggunakan fungsi-fungsi tersebut. Sebuah use case merepresentasikan sebuah interaksi antara aktor (user atau sistem lainya) dengan sistem. Use case menjelaskan secara sederhana fungsi sistem dari sudut pandang user.

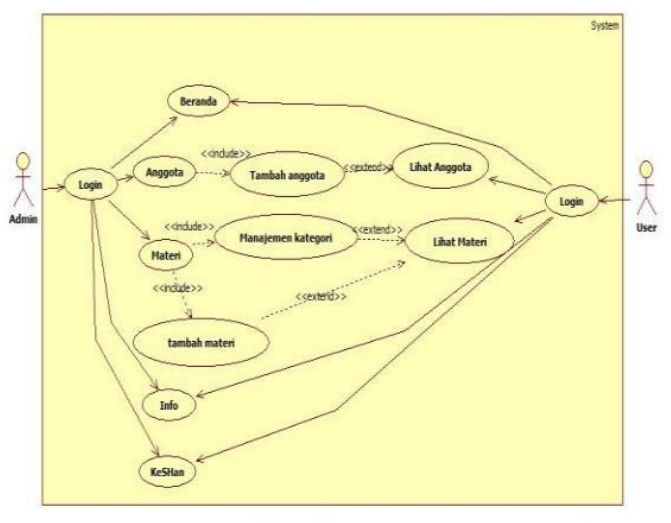

Gambar 1.Use Case Diagram

\section{B. Class Diagram}

Class diagram menggambarkan struktur dan deskripsi class, package dan objek beserta hubungan satu sama lain seperti containment, pewarisan, asosiasi, dan lain-lain. Class diagram dapat dilihat pada gambar 2 :

\section{E. Xampp}




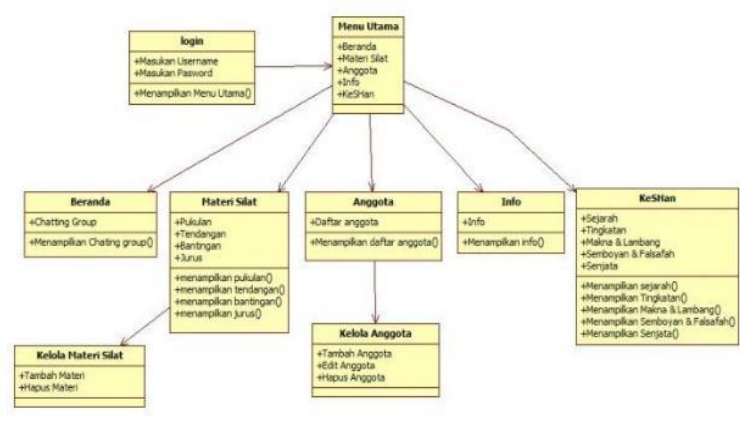

Gambar 2. Class Diagram

\section{Activity Diagram}

Gambar berikut merupakan activity diagram data anggota :

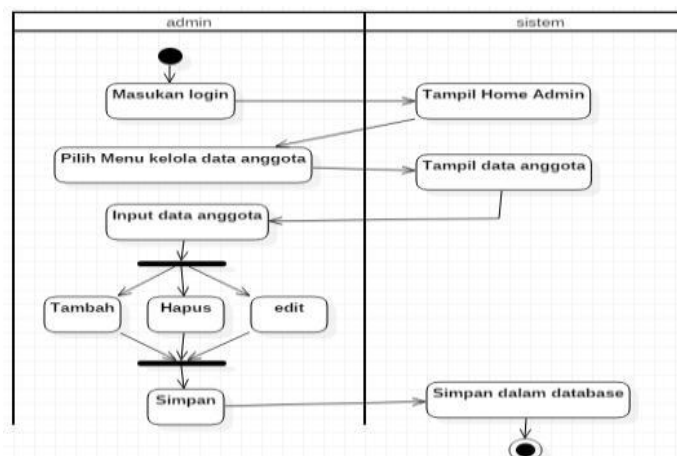

Gambar 3. Activity Diagram Kelola data anggota

D. Sequence Diagram

Gambar berikut merupakan sequence diagram data anggota :

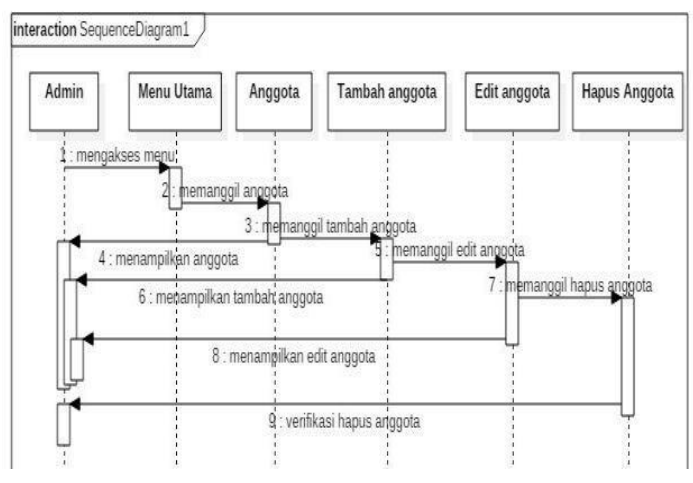

Gambar 4. Sequence diagram kelola data anggota

\section{Implementasi Dan Pembahasan}

Aplikasi ini dapat berjalan dengan ketentuan

1) Perangkat laptop atau handphone memiliki web browser dan jaringan internet;

2) telah terdaftar di aplikasi panduan pencak silat persaudaraan setia hati terate;

3) meinputkan link.
Black box testing yang dilakukan meliputi beberapa pengujian yang dapat dikelompokan pada tabel 1.

\begin{tabular}{cl}
\hline $\begin{array}{c}\text { Nama } \\
\text { Pengujian }\end{array}$ & \multicolumn{1}{c}{ Kriteria Evaluasi Hasil } \\
\hline Login & Ketik URL \\
\hline Login & Masukan username dan password \\
\hline & Salah memasukan usemame dan
\end{tabular}
password Menampilkan pesan salah masukan username dan password dan menampilkan halaman login kembali

\begin{tabular}{|c|c|}
\hline & Mengirim pesan di chatting group \\
\hline $\begin{array}{l}\text { Halaman } \\
\text { Beranda }\end{array}$ & $\begin{array}{l}\text { Admin dan anggota dapat melihat } \\
\text { pesan. Admin ditandai dengan warna } \\
\text { orange sedangkan anggota warna } \\
\text { hitam }\end{array}$ \\
\hline $\begin{array}{l}\text { Halaman } \\
\text { materi }\end{array}$ & $\begin{array}{l}\text { Pilih menu materi Menampilkan } \\
\text { pukulan tendangan bantingan dan } \\
\text { jurus. }\end{array}$ \\
\hline $\begin{array}{l}\text { Halaman } \\
\text { materi silat }\end{array}$ & $\begin{array}{l}\text { Pilih kategori materi Menampilkan } \\
\text { daftar list kategori materi }\end{array}$ \\
\hline $\begin{array}{l}\text { Halaman } \\
\text { materi silat }\end{array}$ & $\begin{array}{l}\text { Pilih daftar list kategori materi dan } \\
\text { sentuh play Menjalankan video }\end{array}$ \\
\hline $\begin{array}{l}\text { Halaman } \\
\text { Anggota }\end{array}$ & $\begin{array}{l}\text { Pilih menu anggota Menampilkan daftar } \\
\text { anggota }\end{array}$ \\
\hline $\begin{array}{l}\text { Halaman } \\
\text { Anggota }\end{array}$ & $\begin{array}{l}\text { Pilih salah satu daftar anggota } \\
\text { Menampilkan biodata anggota }\end{array}$ \\
\hline $\begin{array}{l}\text { Halaman } \\
\text { keSHan }\end{array}$ & $\begin{array}{l}\text { Pilih menu KeSHan Menampilkan } \\
\text { sejarah, makna dan lambang, } \\
\text { semboyan dan falsafah, tingkatan dan } \\
\text { senjata }\end{array}$ \\
\hline $\begin{array}{l}\text { Halaman } \\
\text { keSHan }\end{array}$ & $\begin{array}{l}\text { Sentuh salah satu list } \\
\text { Menampilkan penjelasan }\end{array}$ \\
\hline logout & $\begin{array}{l}\text { Sentuh tombol logout Kembali ke } \\
\text { halaman login }\end{array}$ \\
\hline
\end{tabular}

Selamat Datang Di Aplikasi P:
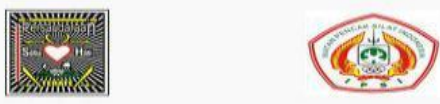

Login

Gambar 5. Halaman login 


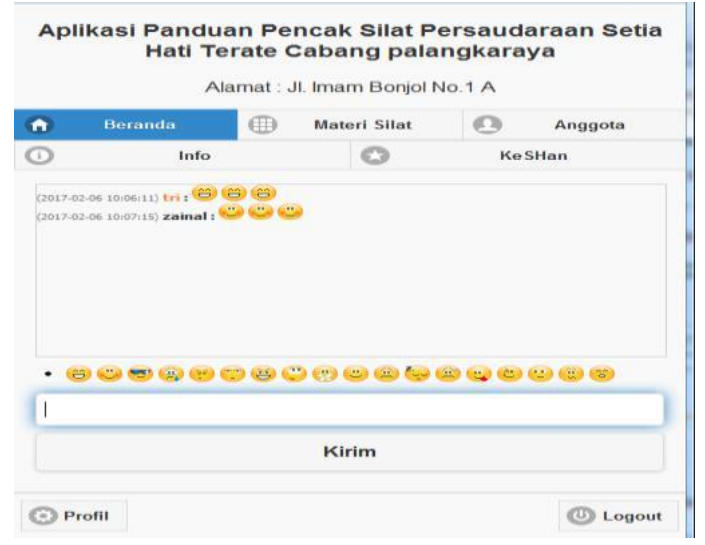

Gambar 6. Halaman beranda

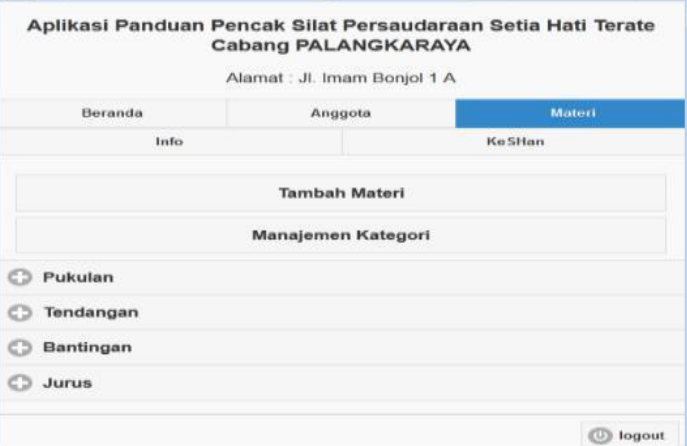

Gambar 7. Halaman Materi silat

Appikasi Panduan Pencak Silat Persaudaraan Setia Hati Terate Cabang PALLNGKaRAYA

Alana: : II inam Bonoli 1 A

unpose

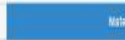

Whan

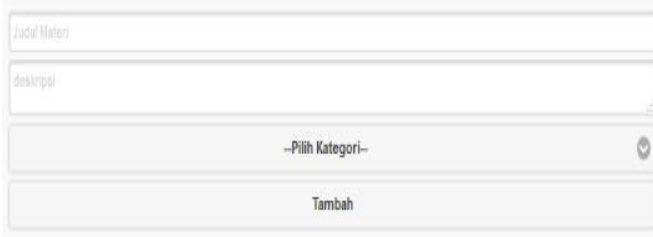

0

Omgout

Gambar 8. Halaman Tambah Materi

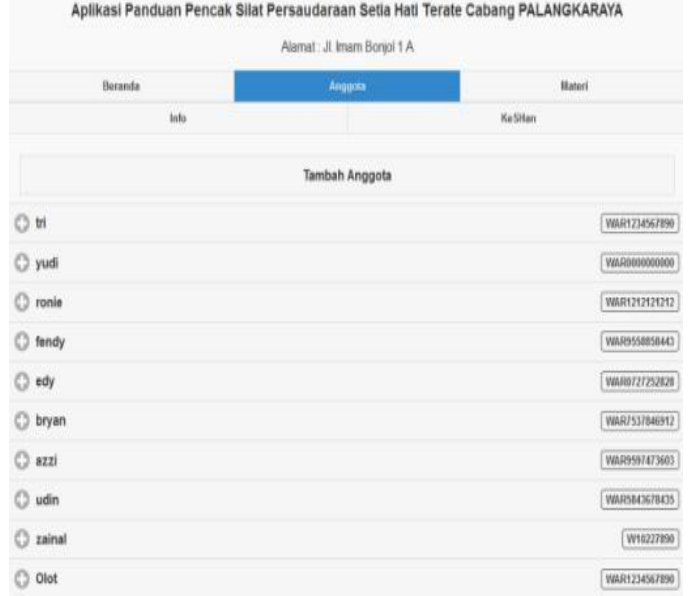

Gambar 9. Halaman Anggota

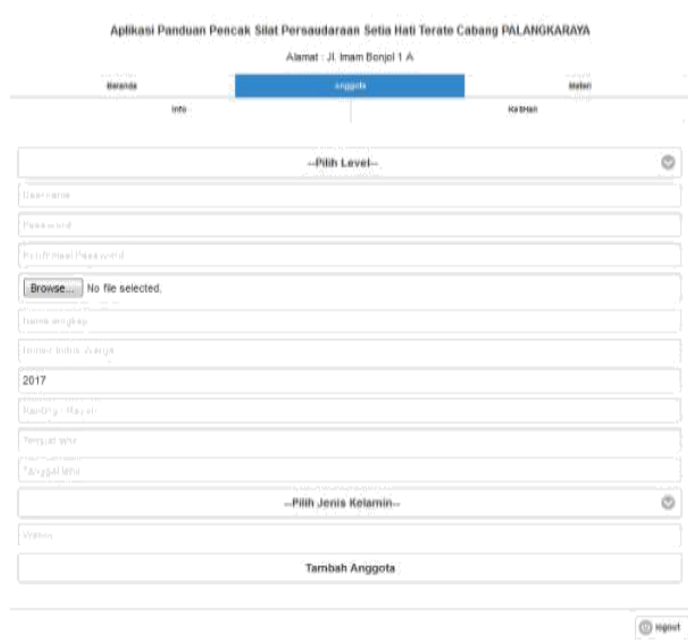

Gambar 10. Halaman Tambah Anggota

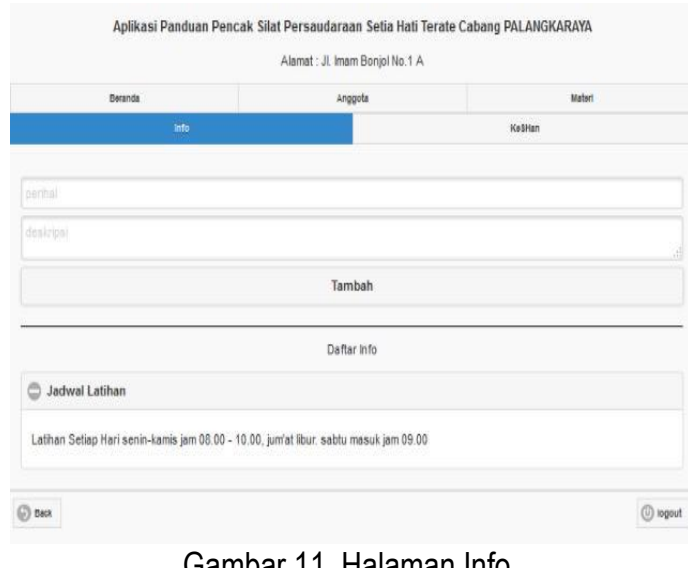

Gambar 11. Halaman Info 


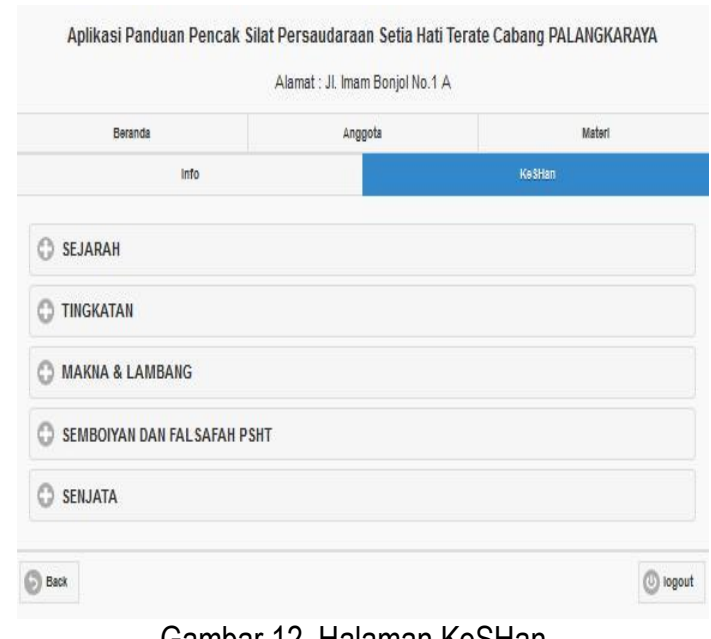

Gambar 12. Halaman KeSHan

\section{Kesimpulan dan Saran}

\section{A. Kesimpulan}

1) Aplikasi website telah berhasil dibuat dengan menggunakan bahasa pemrograman framework jquery mobile dan alat bantu dalam program web yaitu javascript yang digunakan untuk membuat sebuah aplikasi web mobile. Database yang digunakan berbasis Struktured Query Languange (SQL) yaitu MySQL.

2) Hasil dari pengujian black box Aplikasi Panduan Pencak Silat Persaudaraan Setia Hati Terate Berbasis Web Mobile Menggunakan Framework Jquery Mobile sesuai harapan penulis.

\section{B. Saran}

1) Sistem ini hendaknya lebih ditingkatkan lagi dari segi penyajian informasi yang lebik banyak baik berupa pengajaran materi pencak silat untuk anggota Persaudaraan Setia Hati Terate palangkaraya melalui aplikasi web mobile ini.

2) Dapat ditambahkan materi materi yang baru apabila terdapat materi yang belum dimasukan dan dipublikasikan.

\section{Daftar Pustaka}

Andi. 2013. Pengembang Aplikasi Web Mobile. Setia Kawan Peras, Jakarta

Elbarnaz. 2000. Dimensi Moralitas Dalam Pencak Silat. Andi. Yogyakarta.

Habibi. 2009. Sejarah Pencak Silat Indonesia (Studi Historis Perkembangan PSHT Di Madiun Periode Tahun 1922-2000). Institut Agama Islam Negeri Sunan Kalihaga. Yogyakarta

Hakim, 2010. Bikin Website Super Keren Dengan PHP \& jQuery. Lokomedia. Yogyakarta

Haris, Ferdiyani. 2018. Rancang Bangun Aplikasi Ensiklopedia Berbasis Android. Jurnal Sains Komputer dan Teknologi Informasi. Vol 1
Issue 1 e-ISSN 2655-7460.

https://doi.org/10.33084/jsakti.v1i1.448

Kamus Besar Bahasa Indonesia, 2005. Graha IImu, Jakarta

Madcoms. 2009. Aplikasi Program PHP + MySQL Untuk Membuat Website Interaktif, Andi, Yogyakarta.

Nugroho. 2010. Rekayasa Perangkat Lunak Menggunakan UML dan JAVA. Andi, Yogyakarta

Riyanto 2011, Membuat Sendiri Aplikasi Ecommerce dengan PHP dan MySQL Menggunakan Codeigniter dan JQuery. Andi, Yogyakarta.

Sadeli, Muhammad. 2011. 7 Jam Belajar Interaktif Dreamweaver CS5 untuk Orang Awam: Maxikom, Palembang.

Sam'ani. Annisa, S., Heri., 2018. Rancang Bangun Aplikasi Pengawasan Dan Pengendalian Komputer Laboratorium Multimedia STMIK Palangkaraya. Jurnal Sains Komputer dan Teknologi Informasi. Vol 1 Issue 1 e-ISSN 2655-7460. https://doi.org/10.33084/jsakti.v1i1.548

Sam'ani, Qamaruzzaman, M. H, 2019. Rancang Bangun Visualisasi Pembelajaran Berbasis Android Untuk Anak. Jurnal SISTEMASI. Vol 8 No 3 e-ISSN 2540-9719. https://doi.org/10.32520/stmsi.v8i3.518

Sammervile. 2010. Software Engineering (Rekayasa Perangkat Lunak). Erlangga. Jakarta

Septian Gugun., 2011. "Trik Pintar Menguasai Codelgniter", Jakarta : PT Alex Media Komputindo.

Sondakh, 2009. "Olahraga Prestasi", Elex Media Komputindo, Jakarta. 